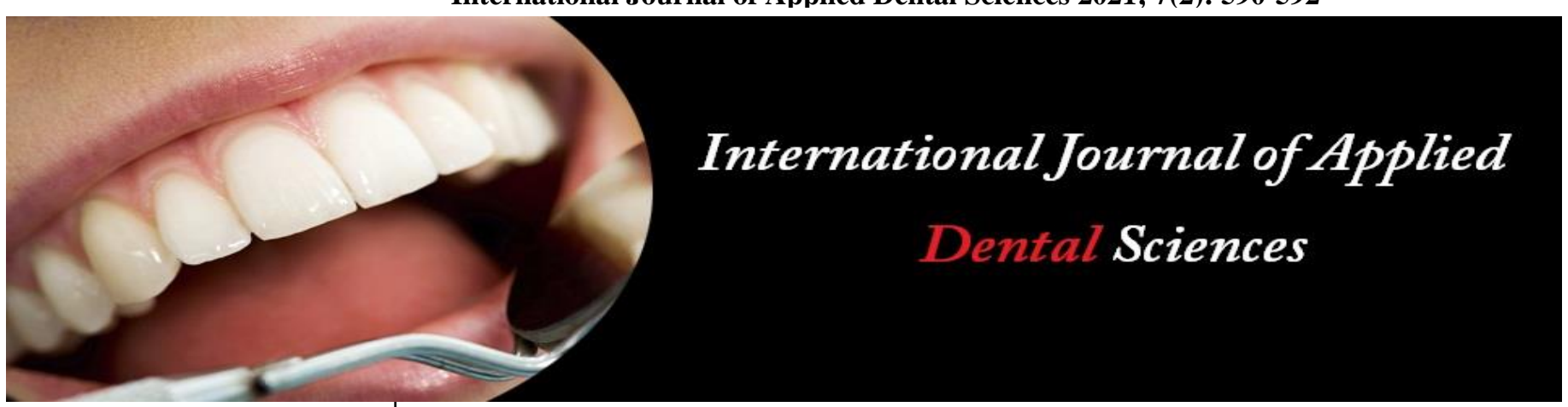

ISSN Print: 2394-7489

ISSN Online: 2394-7497

IJADS 2021; 7(2): 590-592

(C) 2021 IJADS

www.oraljournal.com

Received: 25-02-2021

Accepted: 27-03-2021

Dr. Aarushi Anand

Post Graduate Student,

Rajarajeswari Dental College and Hospital, Rajiv Gandhi

University of Health Sciences,

Bangalore, Karnataka, India

Dr. Gautam Shetty

Professor and Head, Department of Prosthodontics, Rajarajeswari Dental College and Hospital,

Rajiv Gandhi University of

Health Sciences, Bangalore,

Karnataka, India
Corresponding Author:

Dr. Aarushi Anand

Post Graduate Student,

Rajarajeswari Dental College

and Hospital, Rajiv Gandhi

University of Health Sciences,

Bangalore, Karnataka, India

\section{Knowledge and attitude of other professionals towards dentists and dentistry as a profession in Bangalore city}

\author{
Dr. Aarushi Anand and Dr. Gautam Shetty
}

DOI: https://doi.org/10.22271/oral.2021.v7.i2i.1269

\section{Abstract}

Background: Studies have suggested that patient's satisfaction with their dentists is a primary determinant of whether they seek preventive and treatment related dental care. People who are dissatisfied with the interpersonal aspects of their dentists' treatment tend to avoid care and jeopardize their dental health. This survey was conducted to assess attitude of individuals of varied profession towards dentists and the dental profession.

Method: The study was conducted with 227 individuals belonging to profession other than dental or medical from Bangalore city. After obtaining participants's consent a questionnaire was delivered to them and they were asked to mark honest responses. The responses were then collected and evaluated.

Results: Subjects generally had positive attitude toward dentists. Majority of study subjects considered dental services to be expensive. Negative attitudes were observed regarding waiting time.

Conclusion: Dental profession has to take concrete steps to stamp out the unfavorable impressions from the public.

Keywords: dental service utilization, dentists, public attitude

\section{Introduction}

Attitude of individuals of other professions towards health personnel in general, dentists and dental services in particular are a culmination of life experiences and events. Understanding these attitudes helps dental professionals to appreciate the complexities involved in modifying the attitude and behaviour of general public toward oral health care. Public perception of our profession is varied and is changing and it is desirable that dentists be aware of that. Although most dentists are genuinely interested in rendering quality care, making dental visit a comfortable and no stressful experience, public views may not always be consistent with dentists' views ${ }^{[1]}$.

Studies have suggested that patient's satisfaction with their dentists is a primary determinant of whether they seek preventive and treatment related dental care. People who are dissatisfied with the interpersonal aspects of their dentists' treatment tend to avoid care and jeopardize their dental health. Research also has found that the principal factor in dentists' self-reported life stress, practice-related stress and mental distress is a sense that their patients lack respect for the practice of dentistry ${ }^{[2]}$.

This survey focused on research that assessed attitude of individuals of varied profession towards dentists and the dental profession.

\section{Materials and Methods}

The conducted survey evaluated the attitude of youngsters who belonged to the age group of 20-29 years from Bangalore city in Karnataka by including questions that assessed their knowledge and attitude towards dentistry as a profession and dentists in general. Inclusion criteria was that the individuals had to be a resident of Bangalore, belonging to the age group of 20-29 years, who were not related to dental/medical profession by any means and had visited the dentist at least once. A questionnaire was prepared that included 3 sets of questions; a) to assess the participant's general knowledge towards dental health b) to assess the participant's attitude towards the dentists and c) to assess their attitude towards dentistry as 
a profession. A total of 227 responses were collected.

Responses were collected from the participants by keeping their identity anonymous with only their age and educational qualification/profession obtained under the personal information. Two questions were asked to evaluate the individual's knowledge about the dental care i.e. whether "Dentists need to enquire about general overall health" and whether "Dental treatment is a part of overall health care". The participants were required to fill in their responses on a 5 point Likert scale and the options given were, strongly agree, agree, don't know, disagree and strongly disagree. three questions were asked to assess the participant's attitude towards dentistry as a profession, which included," How much Trust or Confidence would you say you have in doctors in general?"," How much Trust or Confidence would you say you have in Dentists in general?" and "How much respect would you say you have for someone who's a dentist?" the options were given as, none, a little, a moderate amount and a great deal. three questions were asked to asses their attitude towards the dentists i.e. whether" Dentists make patients wait for long time?", "Do you think dentists overcharge their patients?" and whether "Dentists treat patients Gently and Painlessly?". the options given were, strongly agree, agree, don't know, disagree and strongly disagree. The participants were also required to fill in the reason for ignoring/delaying a dental visit and the options given were, problem not serious, no time, no problem, fear of pain during dental treatment, cannot afford fees or afraid of dentists. The obtained data was analysed.

\section{Results \& Discussion}

Out of the 227 participants of the survey, $19.9 \%$ individuals belonged to the IT profession, $47.7 \%$ individuals belonged to the commercial sector and the rest belonged to other categories that included various other professions barring the medical or dental professions. Table 1 shows the assessment of the individual's knowledge about the dental care. $57.2 \%$ individuals agreed that the dentists need to enquire about the complete healthcare whereas, only $10 \%$ disagreed. The rest were unsure. $99.4 \%$ of individuals agreed that dental care is a part of overall healthcare.

Table 2 shows the patients responses collected to assess the participant's attitude towards dentistry as a profession.

Table 3 shows the responses of the participants to the questions asked to assess their attitude towards the dentists. $48.3 \%$ participants agreed that dentists make patients wait for a long time. $25.5 \%$ disagreed and the rest $25.5 \%$ were unsure.43.9\% participants agreed that dentists overcharge their patients for treatment.27.6\% disagreed and the rest $27.7 \%$ were unsure. $73.4 \%$ agreed that dentists treat their patients gently and painlessly.12.7\% disagreed and $13.2 \%$ were unsure. Study subjects generally had a positive attitude toward dentists though there were certain areas where the attitude was negative.

among the reasons to ignore dental visit, $35.6 \%$ claimed to do so due to fear of pain during dental treatment, while the rest, $15.8 \%, 14.9 \%, 11 \%$ and $2 \%$ belonged to the reasons categorised as, "can't afford fees", "afraid of dentists", "problem not serious" and "no time" respectively. majority of study subjects feel that dental services are expensive

The present study was undertaken to explore the attitude of individuals from various other professions towards dentists and dental services in Bangalore city. The questionnaire had statements regarding dentists and dentistry as a profession, the subjects' level of satisfaction with the dental services. In the present study, people who have visited a dentist at least once were involved. This trend is similar to the findings of the study conducted by Zhu et al. ${ }^{[3]}$ in China where only $68 \%$ of 35-44 years old subjects had made at least one dental visit in their lifetime. The probable reason may be that people in the Indian subcontinent mainly rely on home remedies for ailments before consulting a doctor or a dentist. p. In a study conducted by Newman and Gift ${ }^{[4]}$ it was reported that $53 \%$ of people in USA regularly visit dentist even when there is no problem. This vast disparity may be attributed to the lack of awareness of the study population regarding the role played by regular dental visits in preventing dental diseases. The presence of dental insurance in USA facilitates the public to visit a dentist regularly.

About 48.3\% \% respondents agreed that "dentist makes patients wait for a long time." Contrasting results were obtained in a study done in UK, ${ }^{5}$ where only $24 \%$ respondents agree to a similar statement. This indicates the downbeat attitude of respondents in the present study toward the time scheduling of dentists. In the present study, $57.2 \%$ agree that "dentists need to enquire about general health." Whereas in the study done by Lin et al. in China, ${ }^{[6]}$ nearly $90 \%$ of the subjects agreed that dentists need to enquire about general health. Hence awareness needs to be created in the public about the relation between oral health and general health.

About $43.9 \%$ of the respondents agreed that dentists overcharge their patients. There is a notion that dentist can be ruthless at times as $12.7 \%$ of respondents feel that dentists do not treat gently and painlessly. This shows that the respondents in the present study are clearly disappointed about the cost of dental treatment. It may be because patients themselves have to bear the costs of treatment in India. it becomes essential for dentists to live up to the expectations of public.

$35.6 \%$ of respondents agree that fear of pain prevents them from utilizing dental services. This negative attitude may be due to the misconception that dental treatment is always painful.

The present study is a first step in assessing the public attitude toward the dental profession. The questionnaire used was tested for face validity and content validity, but its reliability was not assessed, which becomes a limitation of the study. Since this is a descriptive study, it only provides overview of public perception. Further analytical studies are needed to analyse factors which lead to formation of positive and negative attitudes of general public towards dental profession.

\subsection{Tables and Figures}

Table 1: Assessment of The Individual's Knowledge About the Dental Care.

\begin{tabular}{|c|c|c|c|c|c|}
\hline & $\begin{array}{c}\text { Percentage of } \\
\text { Strongly disagree }\end{array}$ & $\begin{array}{c}\text { Percentage of } \\
\text { Strongly agre }\end{array}$ & $\begin{array}{c}\text { Percentage of } \\
\text { Don't know }\end{array}$ & $\begin{array}{c}\text { Percentage of } \\
\text { Disagree }\end{array}$ & $\begin{array}{c}\text { Percentage } \\
\text { of agree }\end{array}$ \\
\hline $\begin{array}{c}\text { Dentists need to enquire about } \\
\text { general overall health }\end{array}$ & 0.8 & 28.6 & 9.68 & 9.2 & 28.6 \\
\hline $\begin{array}{c}\text { Dental treatment is a part of } \\
\text { overall health care? }\end{array}$ & 1.32 & 58.5 & 4.8 & 1.7 & 40.9 \\
\hline
\end{tabular}


Table 2: Responses Collected to Assess the Participant's Attitude Towards Dentistry as A Profession.

\begin{tabular}{|c|c|c|c|c|}
\hline & $\begin{array}{c}\text { Percentage of A } \\
\text { great deal }\end{array}$ & $\begin{array}{c}\text { Percentage of A } \\
\text { little }\end{array}$ & $\begin{array}{c}\text { Percentage of A } \\
\text { moderate amount }\end{array}$ & $\begin{array}{c}\text { Percentage of } \\
\text { none }\end{array}$ \\
\hline $\begin{array}{c}\text { How much Trust or Confidence would you say } \\
\text { you have in doctors in general ? }\end{array}$ & 27.7 & 11.8 & 58.0 & 1.76 \\
\hline $\begin{array}{c}\text { How much Trust or Confidence would you say } \\
\text { you have in Dentists in general ? }\end{array}$ & 27.2 & 11.8 & 58.0 & 2.2 \\
\hline $\begin{array}{c}\text { How much respect would you say you have for } \\
\text { someone who's a dentist? }\end{array}$ & 46.2 & 10.5 & 40.4 & 2.2 \\
\hline
\end{tabular}

Table 3: Responses of The Participants to The Questions Asked to Assess Their Attitude Towards the Dentists

\begin{tabular}{|c|c|c|c|c|c|}
\hline & $\begin{array}{c}\text { Percentage of } \\
\text { Strongly disagree }\end{array}$ & $\begin{array}{c}\text { Percentage of } \\
\text { Strongly agree }\end{array}$ & $\begin{array}{c}\text { Percentage of } \\
\text { Don't know }\end{array}$ & $\begin{array}{c}\text { Percentage of } \\
\text { Disagree }\end{array}$ & $\begin{array}{c}\text { Percentage of } \\
\text { agree }\end{array}$ \\
\hline $\begin{array}{c}\text { Dentists make patients wait } \\
\text { for long time? }\end{array}$ & 3.5 & 14.0 & 25.5 & 22 & 34.3 \\
\hline $\begin{array}{c}\text { Do you think dentists } \\
\text { overcharge their patients? }\end{array}$ & 4.8 & 14 & 27.7 & 22.8 & 29.9 \\
\hline $\begin{array}{c}\text { Dentists treat patients Gently } \\
\text { and Painlessly? }\end{array}$ & 1.7 & 20.2 & 13.2 & 11 & 53.2 \\
\hline
\end{tabular}

\section{Conclusions}

Subjects generally had positive attitude toward dentists. Majority of study subjects considered dental services to be expensive. Negative attitudes were observed regarding waiting time. Dental profession has to take concrete steps to stamp out the unfavourable impressions from the public.

\section{References}

1. Ravindranath NS, Manikyam A. Public attitude towards dentists and dental services in Bangalore city, India. Journal of Indian Association of Public Health Dentistry. 2014;12(2):100

2. DiMatteo MR, Mcbride CA, Shugars DA, O'neil EH. Public attitudes toward dentists: a US household survey. The Journal of the American Dental Association 1995;126(11):1563-70.

3. Zhu L, Petersen PE, Wang HY, Bian JY, Zhang BX. Oral health knowledge, attitudes and behaviour of adults in China. Int Dent J 2005;55:231-41

4. Newman JF, Gift HC. Regular pattern of preventive dental services - A measure of access. Soc Sci Med 1992;35:997-1001.

5. Williams SJ, Calnan M. Convergence and divergence: Assessing criteria of consumer satisfaction across general practice, dental and hospital care settings. Soc Sci Med 1991;33:707-16

6. Lin HC, Wong MC, Wang ZJ, Lo EC. Oral health knowledge, attitudes, and practices of Chinese adults. J Dent Res 2001;80:1466-70. 